\title{
Compreensões da velhice satisfatória em mulheres idosas do Distrito Federal: aspectos da história de vida e as influências da classe social
}

\author{
Fabiana Moreira Lima* \\ ORCID 0000-0001-8261-0029 \\ Universidade Católica de Brasília, Pós-Graduação em Gerontologia, Brasília, Brasil \\ Henrique Salmazo da Silva* \\ ORCID 0000-0002-3888-4214 \\ Universidade Católica de Brasília, Pós-Graduação em Gerontologia, Brasília, Brasil
}

Resumo: O objetivo do presente estudo foi identificar as possíveis influências da classe social sobre a compreensão de velhice satisfatória de mulheres idosas do Distrito Federal (DF). Trata-se de um estudo transversal, exploratório e qualitativo. Utilizou-se a entrevista de história de vida para compreender as trajetórias de oito participantes de dois grupos de convivência, sendo um em regiáo de baixa-média renda (Ceilândia - grupo C) e o outro de alta renda (Jardim Botânico - grupo JB). A classe social esteve associada ao nível de escolarização, trabalho, matrimônio, ao processo migratório ao DF e a construção da velhice satisfatória. No grupo C, a velhice foi permeada pelo acesso a oportunidades educacionais e a novos bens e serviços; já no grupo JB, por um período de descanso e lazer e proximidade da rede social. Fatores intrínsecos, relacionados ao indivíduo, foram mais relatados pelo grupo $\mathrm{C}$ para descrever velhice satisfatória; e componentes intrínsecos e extrínsecos pelo grupo JB.

Palavras-chave: Idoso. Mulheres. Classe social. Narrativas pessoais. Satisfação pessoal.

Mestre em Gerontologia pela Universidade Católica de Brasília (UCB). E-mail: fabianaml@yahoo. com.

* Prof. Doutor em Gerontologia da Universidade Católica de Brasília (UCB).E-mail: henriquesalmazo@ yahoo.com.br. 


\title{
Understandings of satisfactory old age in elderly women in the Federal District: features of life story and the social class influences
}

\begin{abstract}
The objective of the present study was to identify the possible influences of the social class on the understanding of satisfactory old age of elderly women living in the Federal District (FD). This is a cross-sectional, exploratory and qualitative study. The Life History interview was selected as a method to comprehend the trajectories of eight participants of two social groups: group $\mathrm{C}$, with low-middle income, and group JB, with high income. Social class was associated with the level of schooling, work, marriage, the migratory process to the FD and the construction of satisfactory old age. For group C, old age was permeated by access to educational opportunities and new goods and services; in other hand, for grupo $\mathrm{JB}$ as period of rest, to enjoy leisure and their social network. Intrinsic factors, related to the individual, were more reported by group $\mathrm{C}$ to describe satisfactory old age, and intrinsic and extrinsic components by group JB.
\end{abstract}

Keywords: Elderly. Women. Social class. Personal narratives. Personal satisfaction.

\section{Introdução}

Se a sua vida fosse um livro, como você começaria contando a sua história? Assim começou a nossa jornada pela vida de oito mulheres. Com distintas idades, estruturas familiares, contextos socioeconômicos. Mas unidas por um ponto comum: mulheres saudáveis, com bom desempenho cognitivo, boa saúde psicológica e que vivenciam a velhice de maneira satisfatória.

Chegar à velhice pode ser uma experiência vivenciada de forma ambígua: de um lado, a possibilidade de aproveitar cada minuto da vida que se tem; de outro, enfrentar as diversas mudanças que essa fase pode provocar. Desta forma, ao discutirmos sobre envelhecimento é primordial levar em consideração a realidade dos atores sociais que o vivenciam, bem como compreender o contexto no qual estáo inseridos (Alberte, 2009; Debert, 1999).

A partir do ponto de vista da Gerontologia, que foi o nosso arcabouço teórico norteador, buscamos responder algumas questóes acerca do impacto de eventos de vida e dos aspectos socioeconômicos na compreensão dessas mulheres sobre as suas vidas e o seu processo de envelhecimento. No entanto, as discussóes apresentadas neste artigo serão voltadas às possíveis influências da classe social sobre a compreensão subjetiva de velhice satisfatória, sendo este um recorte do trabalho que é parte integrante de uma dissertação de mestrado com o título: Trajetórias do envelhecimento: a construção de uma velhice satisfatória sob a perspectiva de mulheres idosas de diferentes classes sociais. A investigação realizada se justifica pelo crescente processo de feminilizaçáo da velhice, pelas transformaçóes sócio-históricas acerca dos papéis da mulher ao longo do século XX e, paralelamente, pelo papel que a classe social pode exercer nas vivências de 
envelhecimento e velhice (Lima, 2020).

A história oral consiste em um recurso metodológico o qual permite estudar a experiência social de indivíduos e grupos, além de possibilitar conhecer diferentes visóes de mundo a partir de múltiplas narrativas, demonstrando que cada experiência, embora seja única, se constitui como parte de um todo (David, 2013; Meihy, 2000). Embora haja críticas sobre a credibilidade das fontes orais, Portelli (1997) contrapóe essa visão argumentando que, independente da veracidade proveniente das narrativas, a diversidade e riqueza da história oral consiste no fato de que mesmo relatos distorcidos trazem a "verdade" psicológica do narrador, o que faz com que seu relato seja tão importante quanto registros factuais.

Embora a história oral, historicamente, tenha surgido após a história de vida, há autores que defendem a segunda como uma das modalidades da primeira (Silva, 2002; Meihy, 2000). De toda forma, torna-se importante trazer uma breve discussão acerca das aproximaçóes e distanciamentos entre esses métodos de pesquisa biográfica.

A história oral apresenta um caráter mais objetivo, utilizando-se de questionários estruturados, com foco na experiência do sujeito ou grupos acerca de um evento histórico específico. Esse método permite uma aproximação maior com a realidade na qual o sujeito está inserido e não há, necessariamente, uma preocupação acerca do vínculo entre narrador e pesquisador (Meihy, 2000; Silva et al., 2007; Silva, 2002). Por outro lado, a história de vida contribui no processo de reconstrução de si a partir da emergência de sentidos que são construídos por meio da troca relacional entre narrador e ouvinte durante a narração sobre a sua trajetória (Carvalho; Costa, 2015; Guedes, 2014; Machado, 2010). Nessa modalidade, o narrador (ou seja, aquele que está compartilhando a sua história) apresenta maior liberdade para relatar suas experiências de vida; tal recurso permite ao pesquisador entender não apenas como a pessoa experiencia a sua vida como também seu processo de compreensão acerca dela (Atkinson, 1998).

O método história de vida, dessa forma, se encaixa neste objeto de investigação por permitir compreender os significados e os fenômenos associados ao curso de vida e ao processo de envelhecimento de uma geração de mulheres brasileiras de diferentes classes sociais do Distrito Federal (DF) que nasceram no século XX e cruzaram o século XXI. O período sócio-histórico investigado é deflagrado por uma intensa globalização, urbanização, fortes influências sociopolíticas, processo migratório, ampliação da atuação da mulher nos espaços de trabalho e reconfiguraçôes na vida social e conjugal, destacando o impacto das desigualdades pré-existentes no país e a sua evolução no decorrer dos anos (Lima, 2020).

A velhice é resultado de um percurso complexo, multideterminado e dinâmico que demanda adaptaçóes e/ou regulação das perdas físicas, das transições familiares e das mudanças de papéis sociais. Acredita-se, então, que haja uma inter-relação entre desigualdade social e a velhice a partir da perspectiva de que ambas venham a exigir 
uma variedade de estratégias compensatórias orientadas para o bem-estar e qualidade de vida do idoso (Lima, 2020).

Quando falamos sobre envelhecimento, não buscamos apenas fazer uma retratação do passado, mas também permitir que essa discussão chegue a nós, jovens e adultos de hoje que seremos os velhos de amanhá. Considerando que a nossa perspectiva enquanto pesquisadores era ter uma visáo ampliada sobre a trajetória de mulheres idosas, a escolha de se utilizar a entrevista de história de vida, demonstrou ser uma escolha assertiva dentro do nosso propósito, isso porque, esse método remete à essência do ocorrido na vida de uma pessoa, podendo abranger desde seu nascimento até o presente; de toda forma, ela possibilita trazer à tona os principais acontecimentos, experiências e sentimentos da trajetória de vida (Atkinson, 1998).

Ao buscar trabalhar com histórias de vida, é essencial termos a sensibilidade de compreender que estamos lidando com pessoas que podem ou não compreender a importância que se tem quando elas compartilham suas trajetórias. Nós, pesquisadores, pedimos licença para sermos espectadores de realidades rodeadas de dores, alegrias, segredos familiares, perdas e conquistas, no entanto, sem esquecer que são mundos que não nos pertencem, além de ser um contexto sócio-histórico diferente ao qual pertencemos. A postura do entrevistador, assim como o vínculo criado, passa a ter um papel determinante para que os narradores possam se sentir à vontade ou não para compartilhar suas histórias. Desta forma, como afirmam Leite, Silva e Lima (2020), para a formação de vínculo e aproximação com os entrevistados pode ser necessário mais de um encontro ou mesmo a participação nas atividades rotineiras dessas pessoas.

As aproximaçóes com as participantes foram realizadas em momentos distintos entre os dois grupos, nas regiôes administrativas Ceilândia (C) e Jardim Botânico (JB) do Distrito Federal, sendo consideradas como regióes de baixa/média e alta renda, respectivamente. Com o primeiro grupo, foram realizados encontros semanais para formação de vínculo e confiança antes do convite para que elas participassem da pesquisa. Com o segundo, a abordagem foi mais diretiva até pelo fato de, no centro de convivência, as idosas já terem o contato com uma psicóloga - o que não ocorria no primeiro grupo. No entanto, mesmo com o segundo grupo, as idosas tiveram contato com um dos pesquisadores ao menos em dois momentos antes da entrevista. Além disso, com todas as participantes buscamos interagir de forma leve e espontânea desde o primeiro momento, a fim de que as idosas pudessem nos ver como indivíduos e não apenas como coletores de dados.

Para uma melhor organização e apresentação dessas trajetórias, organizamos o presente artigo em categorias que se mostraram como aspectos essenciais dentro do objetivo proposto. Primeiramente, faremos uma breve apresentação de aspectos sociodemográficos das narradoras, seguido das categorias: classe social, educação, trabalho, migração para o DF, papéis sociais e, por fim, velhice satisfatória. 


\section{Conhecendo as narradoras}

As entrevistas foram realizadas com oito mulheres idosas, sendo quatro de cada região administrativa ( $\mathrm{C} \mathrm{e} \mathrm{JB}$ ). Elas foram selecionadas, inicialmente, mediante avaliação de aspectos objetivos tais como: ausência de sintomas característicos de humor deprimido, aspectos econômicos e saúde cognitiva. Após essa primeira etapa, as idosas foram orientadas sobre como ocorreria a segunda etapa da pesquisa, sendo possível que elas tirassem as dúvidas que surgiram para posterior agendamento das entrevistas.

Como forma de situar o leitor acerca das participantes que citaremos neste artigo, apresentaremos uma breve síntese sobre cada uma delas. Os nomes utilizados são fictícios a fim de manter o anonimato das participantes.

Do grupo C, temos as narradoras Fernanda, Tânia, Joana e Renata. Fernanda tem 68 anos, casada e com sete filhos. Nasceu no interior do Rio Grande do Norte, sendo a mais velha de seis irmãos. Casou-se com 23 anos. Autodeclarou-se como analfabeta e foi avaliada como pertencendo à classe social $\mathrm{D}$, sendo que nessa análise de classe utilizamos o conceito da Associação Brasileira de Empresas de Pesquisa (ABEP). Tânia tem 70 anos, casada e com cinco filhos. Também nasceu no interior do Rio Grande do Norte. Teve quinze irmáos. Casou-se com 17 anos. Autodeclarada analfabeta. Classe social C1. Joana tem 73 anos, é viúva e teve treze filhos - embora dois tenham falecido. Nasceu no Piauí e teve dez irmãos. Casou-se com 15 anos. Autodeclarou-se analfabeta. Classe social C2. Renata tem 72 anos, quatro filhos e é viúva. Nasceu no Piauí, é a filha caçula de quatro irmáos. Declarou ter o ensino fundamental I incompleto. Classe social C2.

Já do grupo JB, temos as narradoras Nadir, Amanda, Marília e Marta. Nadir tem 71 anos, solteira, sem filhos. Nasceu no interior do Espírito Santo, sendo a filha caçula de seis irmãos. Escolheu não se casar e nem vivenciar a gestação, embora tenha vivenciado a maternidade de forma indireta, com sobrinhos, por exemplo. Tem superior completo. Classe social A. Amanda tem 79 anos, viúva, uma filha. Nasceu no Rio de Janeiro. Tem dois irmãos mais novos. Ensino médio completo. Classe social A. Marília tem 82 anos, divorciada, quatro filhos. Nasceu na Espanha. É filha única. Casou-se com pouco mais de 20 anos. Ensino superior completo. Classe social A. Marta tem 81 anos, viúva, quatro filhos. Nasceu em Minas Gerais, tem três irmãos. Casou-se por volta dos 30 anos. Ensino superior completo. Classe social A.

Ao narrar suas trajetórias, as participantes destacaram como elementos-chave a origem, as transiçōes e mudanças na configuração familiar, o enfrentamento de situaçóes adversas, as oportunidades educacionais e profissionais, bem como a vivência do envelhecimento, aposentadoria e velhice. Embora existam elementos que possam ser comuns entre as mulheres de classe social semelhantes, cada participante possui uma trajetória, escolhas e vivências singulares, elementos que as constituem ora como autoras - com uma postura ativa - ora como personagens - com uma postura mais 
passiva - diante das próprias experiências e reminiscências:

Então, eu nasci numa cidade do estado do Rio chamada de [nome omitido], e sou a mais velha de dois irmãos, tenho um irmão, é dois anos mais novo do que eu; e ficamos lá nessa cidade até... eu tinha uns seis anos por aí; aí nós mudamos para o Rio Grande do Sul. Aí, muitas vezes, eu, meu irmão e meus primos temos vontade de escrever sobre essa mudança porque foi uma saga, né? (Amanda, [JB], 2019).

Do jeito que Deus dava, né? Aí a gente foi crescendo e foi vivendo assim, né? Depois foi trocando de cidade, assim... de lugar, de interior e fomos sobrevivendo, né? Mas graças a Deus que o meu pai, sim, é... é... nunca deixou a gente faltar. (Fernanda, [C], 2019).

No grupo C, todas nasceram na regiáo Norte do país, a maioria em ambiente rural e apresentaram maiores dificuldades no que se refere à subsistência. As participantes desse grupo, em sua maioria, não tiveram acesso à educação formal na infância ou adolescência devido à necessidade de realizar as atividades domésticas. Todas se casaram ainda jovens (na faixa dos 15 aos 20 anos), demonstrando o quanto o matrimônio era algo extremamente valorizado à época e, para elas, representou ainda a possibilidade de melhorar de vida, como na fala a seguir:

Disseram: 'você arrumou seu namorado e vai casar' [risos]. Por que lá tem que casar nova porque se ficar veia os rapaz não quer mais não porque diz que já passou da idade. (Joana, [C], 2019).

No contexto histórico, elas nasceram no período de 1947 a 1951 - época de transiçấo de governo e consolidação da democracia, mas em que a população brasileira era essencialmente rural.

Enquanto que no JB parte das mulheres nasceram na região Sudeste e uma na Espanha, sendo que apenas uma nasceu em ambiente rural. Diferente das idosas do grupo $\mathrm{C}$, este grupo teve acesso à educaçáo formal desde a infância e pôde ascender socialmente por meio do trabalho. Embora tenham vivenciado experiências que elas consideram como negativas, o vínculo familiar se mostrou como uma importante rede de apoio desde a infância. Acerca do contexto histórico, elas nasceram entre os anos de 1937 e 1948, vivenciando ainda na infância o período do governo de Getúlio Vargas, bem como o início e término da Segunda Guerra Mundial.

[...] É... Em 40... 47... um pós-guerra... e eu era a mais velha de duas famílias que, no caso, a gente mudou para Rio Grande do Sul e foi a família do meu pai e a do irmão e o meu tio também, né? E resolveram ir e eles já estavam lá trabalhando; eles trabalhavam em empreiteira de obra né? Então... lá eles tavam em um...um... uma obra grande, né, lá no sul, fronteira mesmo com o Uruguai. (Amanda, [JB], 2019). 


\section{Classe social}

A classe social foi observada como um constructo que influenciou, direta ou indiretamente, ao longo da trajetória dessas mulheres a partir das oportunidades que todas puderam ter ou náo, especialmente no tocante ao acesso à educaçáo e a melhores posiçôes no mercado de trabalho.

No entanto, na visão dessas mulheres, essa influência foi verbalizada com maior ênfase na fase da infância/adolescência, período em que elas perceberam as consequências do preconceito de classe ou a dificuldade de acesso a bens. Os trechos a seguir demonstram as percepçóes sobre a influência da diferença de classe social na vida de duas idosas:

[...] no grupo escolar, na cidade [...] havia muito assim, diferença de classe social. Porque médico é... fazendeiro, essas pessoas do tipo tinham um tratamento. A gente que era pobre tinha outro tratamento. (Nadir, [JB], 2019).

Piauí tinha as festas juninas, boi-bumbá, muita coisa. Lá tem muita cultura. [...] É como se diz, a gente não era daquele nível. Porque parece que... o... o... como se diz, assim, isso é pra gente mais elevada. (Renata, [C], 2019).

Essas falas nos mostram uma realidade acerca do tratamento diferenciado que se tinha no ambiente escolar - no caso de Nadir - e a dificuldade de acesso ao lazer e à cultura - no caso da Renata -; que, em resumo, demonstram um processo de inferiorização dessas pessoas por não terem renda suficiente, o que nos remete a uma ampla discussão das relaçóes de poder atreladas ao conceito de classes. O nosso interesse, no entanto, é mostrar, dentro da perspectiva individual, o quanto essas mulheres demonstraram (ou não) ter consciência de classe.

Segundo as narrativas, para as idosas que vieram de uma classe média-baixa, acompanhar as dificuldades enfrentadas pelos pais foi um fator motivador para que elas quisessem ter um futuro diferente; no entanto, as do grupo JB utilizaram-se dos estudos e da escolarizaçáo formal como forma de crescimento e mobilidade social, enquanto as do grupo $\mathrm{C}$, o casamento foi a forma que elas encontraram de mudar de vida. Por outro lado, mesmo náo tendo acesso a tantos bens, as participantes do grupo $\mathrm{C}$ não demonstraram ter consciência da influência da classe social como um fator determinante em suas vidas, mesmo apresentando maiores dificuldades para garantir a subsistência e sobrevivência da família, se comparadas ao grupo JB. Como pode ser percebido na fala a seguir:

E a minha mãe trabalhava na casa dos brancos, como se sabe que... ainda existia esse termo, da passadeira, cozinheira, na casa dos brancos. Dos doutor. Então, ela saía de manhã e chegava às 6 horas da tarde. Como ela náo podia me levar, a 
empregada não podia levar o filho, eu ficava em casa. (Renata, [C], 2019).

A partir dessa fala da Renata, podemos perceber o entrelaçamento entre as questóes de gênero, classe e raça e o impacto desse contexto macrossocial na construção de suas individualidades. Essa relação é discutida por Cho, Crenshaw e McCall (2013), a partir do conceito de interseccionalidade. De acordo com Hirata (2014, p. 61):

Nessa perspectiva, a ideia de um ponto de vista próprio à experiência e ao lugar que as mulheres ocupam cede lugar à ideia de um ponto de vista próprio à experiência da conjunção das relaçóes de poder de sexo, de raça, de classe, o que torna ainda mais complexa a noção mesma de "conhecimento situado", pois a posiçáo de poder nas relaçóes de classe e de sexo, ou nas relaçóes de raça e de sexo, por exemplo, podem ser dissimétricas.

Por meio desse conceito, permite-se a apreensão da complexidade das identidades e desigualdades sociais a partir de uma visão interdisciplinar (Bilge, 2009). Compreendemos que a construção de quem elas são se pauta em diversos fatores e que a interação desses fatores também influencia na sua velhice, afinal, eles acabam repercutindo nas escolhas que elas fizeram ao longo da vida, assim como na atual fase em que se encontram.

\section{Educação}

As dificuldades vivenciadas pelo grupo JB se mostraram como elementos motivadores para que elas construíssem seus projetos de vida e buscassem no estudo a construção de uma vida com independência. No grupo C, o trabalho e a necessidade de subsistência foram vistos como elementos prioritários para si e para a família, demonstrando que a escolarizaçáo ou busca de um rearranjo social náo existiram devido a uma escolha e sim por uma dificuldade de acesso ou por ser um ideal que talvez não pudesse ser concretizado na fase da infância/adolescência.

Os depoimentos a seguir demonstram o exemplo de duas idosas que tiveram oportunidades de estudo, mas que escolheram caminhos diferentes, trazendo o impacto da subjetividade na apropriação de suas escolhas e trajetórias.

Eu consegui, me formei, fiz o meu curso normal, numa escola de freira lá, um colégio bom, eu tinha minha bolsa. (Amanda, [JB], 2019).

Mais porque eu nunca tentei, mais quando eu cheguei aqui em Brasília meu esposo falou: 'eu vou te matricular no colégio pra tu estudar'. Aí eu disse: 'não vou não, eu tenho os meus filhos, com quem vou deixar meus filhos'. Daí eu não fui, se eu 
tivesse ido, porque eu era nova, eu tinha aprendido; não fui. [...] agora, depois de veia, tenho 73 anos, é que vim estudar. (Joana, [C], 2019).

Das participantes do grupo JB, apenas Amanda não cursou o ensino superior. Marta conseguiu se formar com cerca de 30 anos, mesmo com a oposição do marido. Já em relação ao grupo C, Fernanda, Joana e Tânia se autodeclararam analfabetas; para essas participantes, o grupo de convivência que frequentam na velhice permitiulhes ter acesso ao ensino formal, algo que não puderam durante outras fases da vida. Nesse aspecto, a oferta de programas educacionais voltados para idosos representa a oportunidade de consolidar novos aprendizados e ter acesso a novas experiências de vida, de forma que a possibilidade de aprender permanece latente e robusta ao longo de todo o processo de desenvolvimento humano (Camargo et al., 2018).

Outro aspecto marcante no grupo $\mathrm{C}$ pode ser exemplificado a partir da fala da Renata, que destacou que os ensinamentos que ela teve foram provenientes das experiências de vida; esse é um ponto importante de se destacar, pois, de fato, existem conhecimentos que não são abarcados pelo ensino formal e que, nem por isso, podem ser considerados como inferiores ou inválidos.

O mundo ensina, a vida é uma escola. A gente náo precisa sair e ir pra sala de aula pra aprender muita coisa, náo. (Renata, [C], 2019).

Nesse aspecto, o acúmulo do conhecimento instrumental, ou voltado para a resolução dos problemas da vida, pode ter sido uma habilidade desenvolvida no grupo C como possibilidade de enfrentamento das situaçóes desafiadoras relativas à manutenção das condiçóes básicas de vida e aos desafios impostos na inserção no mundo do trabalho.

\section{Trabalho}

A profissão exercida por essas mulheres na fase adulta sofreu influência da escolarização formal. No grupo JB, o trabalho como datilógrafa, secretária e professora eram funções que apresentavam um status social na época; enquanto no grupo $\mathrm{C}$, as funçóes realizadas eram voltadas basicamente para o trabalho braçal e doméstico. Nesse aspecto, retomamos a ideia acerca dos possíveis impactos acerca de raça e gênero como determinantes sociais dentro dessas trajetórias.

A renda influenciou a manutenção do status quo das participantes do grupo JB, já que, por terem condiçóes financeiras, elas podiam arcar para ter o suporte de pessoas que atuavam como diaristas ou empregadas domésticas ou mesmo contavam com o apoio materno para que fosse possível trabalhar, estudar e cuidar dos filhos, por 
exemplo. No caso do grupo C, elas precisavam levar os filhos para o trabalho ou deixálos em casa sozinhos para que pudessem trabalhar.

Por outro lado, observamos que o trabalho tinha um caráter positivo em suas vidas, não apenas por lhes propiciar o sustento familiar, como por ser um suporte social - a partir das relaçóes que o emprego lhes proporcionava -, e, ainda, por proporcionar independência financeira (no caso do grupo JB). Joana, que relatou trabalhar desde os 12 anos de idade, ajudando os pais na roça, compartilhou que - apesar do esforço e sofrimento - o trabalho tem uma perspectiva de dignidade, representando o quanto a subjetividade tem peso nesse aspecto:

Oxê, é bom demais o trabalho, se a gente não tiver trabalho não tem como ir em canto nenhum... porque não tem um dinheiro, como é que vai? Não pode! Tem que todo mundo trabalhar. (Joana, [C], 2019).

\section{Migração para o DF}

O processo migratório para Brasília foi um marco vivenciado por todas as participantes, porém em situaçóes bem distintas. Dentro do contexto de vida das idosas, um fator que contribuiu para esse deslocamento no grupo JB foi o fato de elas terem uma rede social de apoio e contatos na cidade (algum membro da própria família ou da família do cônjuge); no caso do grupo C, apenas Renata relatou ter vindo por conta de filhos que já moravam na capital federal.

Levando em consideração a disparidade de contextos de vida apresentados pelas idosas, alguns pontos merecem destaque. O primeiro aspecto diz respeito ao núcleo familiar que elas tinham na época em que se mudaram: metade das idosas de ambos os grupos se mudaram já com filhos, enquanto a outra metade já residia em Brasília quando decidiram se tornar mães. Essa realidade já demonstra por si mesmo uma disparidade de oportunidades entre os grupos, pois enquanto no grupo JB as mulheres que já eram mães tinham um ou dois filhos, as do grupo $\mathrm{C}$ já vieram com cinco ou seis.

$\mathrm{O}$ segundo aspecto diz respeito ao tipo de trabalho e à moradia: as idosas do grupo JB foram transferidas de seus estados de origem ou se mudaram após aprovação em concurso público - como no caso da Nadir, representada na fala abaixo - e receberam moradia funcional na regiáo central da cidade; enquanto às do grupo $\mathrm{C}$, elas se mudaram "às cegas", sem casa, sem emprego e foram para as regiōes de Taguatinga e Ceilândia, sem ter ideia do que encontrariam ao chegar na cidade, como no caso da Tânia, que precisou abrir máo de tudo que tinha na sua cidade natal para poder encontrar com o marido. 
Eu passei o carnaval, uma semana depois do carnaval teve um concurso aqui de professor. Aí minha irmã: 'Vai, faz!'. Eu ainda falei: 'Eu não vou não, não vou vim embora para Brasília, náo quero vir embora para Brasília'. Vim para cá para Brasília, não. Ah, mas eles insistiram. 'Então, tá! Vou fazer esse negócio'. Fui lá e fiz a prova. E fui embora. Quando chegou... foi em junho, eu fui chamada aqui. Fui chamada, não. Saiu o resultado (inint), o resultado saiu logo em seguida. Eu tava classificada. (Nadir, [JB], 2019).

Ele veio primeiro aqui pra Brasília, né? Já os meus filhos mais velhos tinham 10 anos, e o mais novo tinha 1 aninho, quando ele veio pra cá, né? Aí eu fiquei lá na casona sozinha, a casa enorme [enfatizou], com aqueles 5 filhos, né? [...] eu recebi a carta dele, ele falava que era pra mim vender tudo, que era pra vim embora pra cá. Náo sei, imagina aquela reviravolta que deu no meu cérebro, assim, né? (Tânia, [C], 2019).

Outro aspecto interessante observado na fala das participantes foi acerca da impressão que tinham da cidade. No caso de Nadir, ela já conhecia a cidade e não se via morando aqui, de forma alguma; por outro lado, Amanda, que vinha com frequência a trabalho, amava a cidade e se mudou mesmo sem o marido concordar - sendo que ele se mudou apenas meses depois. No caso do grupo C, nenhuma das idosas conhecia a cidade. Fernanda - no trecho abaixo - trouxe a decepçáo ao chegar no DF, pois era comum famílias se mudarem para Brasília com uma perspectiva de buscar oportunidades de emprego e melhoria de vida, mas não se sabia que nas cidadessatélites - áreas que ficam afastadas do centro da capital - não havia uma infraestrutura e saneamento básico, tal qual na regiáo nobre.

Pra mim não foi aquela Brasília que eu via o povo falar, 'ah, vou morar em Brasília', 'fulano foi embora pra Brasília', 'a família de fulano foi embora pra Brasília, veio buscar a esposa, veio buscar os filhos'. Quando eu cheguei aqui pra mim não era aquela Brasília que o povo tinha falado. Pra mim não era. (Fernanda, [C], 2019).

De forma geral, pôde-se perceber que a história das participantes coaduna com pesquisas sobre o processo migratório no Brasil que afirmam que este processo é motivado essencialmente pela busca em ingressar no mercado de trabalho (no caso das idosas do grupo C) ou melhorar posiçăo (caso do grupo JB) e, consequentemente, melhorar suas condiçôes de vida (Biagioni, 2010; Figueiredo; Zanelatto, 2017).

\section{Papéis sociais}

As narrativas apresentadas por essas idosas nos permitiram vislumbrar também 
sobre alguns dos importantes papéis sociais que as mulheres vivenciam ao longo da vida. O primeiro papel que vamos destacar é o de filhas: as figuras parentais sempre foram motivo de grande respeito e bons exemplos para todas as participantes. Em todos os relatos, o impacto das figuras parentais fora algo primordial ao seu desenvolvimento: todas compartilharam ver neles exemplos de força e resiliência - ao mesmo tempo, como na fala da Fernanda, o medo cercava essa relação:

Eu tinha um medo de apanhar táo grande, pense... porque ela não tinha dó de bater. A máe... Deus ponha ela num bom lugar, porque ela já faleceu, mas ela não tinha... não tinha dó de bater. Se ela falasse assim: 'Venha aqui'. Antes de ela terminar a palavra eu já estava nos pé dela, que eu tinha medo dela bater, porque ela batia mesmo. (Fernanda, [C], 2019).

De forma geral, a educação proveniente dos pais foi uma importante fonte de incentivo em suas vidas, embora de formas distintas. Isso porque no caso do grupo JB, as idosas foram educadas para serem independentes financeiramente, enquanto as do grupo C foram "preparadas" para o casamento e a manutenção do modelo patriarcal. Conforme Azevedo e Sousa (2019, p. 174):

O papel da mulher ao longo da história foi se modificando à medida que a sociedade flexibilizou sua estrutura, e os patriarcais provedores do lar foram cedendo espaço às mulheres engajadas que trabalham fora, educam filhos e administram lares. Hoje, essa realidade atinge seu ápice de desenvolvimento: o público feminino tem se qualificado cada vez mais e agrega ao papel de filha, esposa e máe o papel de profissional bem-sucedida, apesar da discriminação e violência ainda ser uma realidade.

Em relação ao papel de esposas, Fernanda, Renata, Joana e Tânia carregaram consigo a crença de que o respeito estaria atrelado à obediência e, dessa forma, referem ter vivido conforme a vontade dos respectivos cônjuges. Esse aspecto se destaca na história de duas dessas mulheres e é evidenciado após o falecimento dos maridos, indicando que a viuvez representou emancipaçáo e o início de uma nova jornada, conforme depoimento abaixo:

[...] não... Toda vida ele foi bom pra mim... Só que ele não deixava eu sair pra nenhum canto só, eu só saia se fosse com ele. Ele dizia que eu era nova e ele era mais velho, ele tinha ciúme [risos]. [...] Aqui a gente num ia pra canto ninhum, a gente só ficava dentro de casa durmindo... Era... Agora, despois que ele faleceu eu já fui em Caldas Novas, já fui em Aparecida e até no Rio de Janeiro eu já fui. (Tânia, [C], 2019).

Pelo histórico de submissão e após diversas lutas para a emancipação da 
mulher diante da sociedade - a partir da garantia do direito de exercer um trabalho social, de votar, de se divorciar, entre outros - as funçôes exercidas por elas foram se acumulando. Como Vicente (2018) afirmou, o aumento da escolaridade possibilitou o acesso a profissóes de maior prestígio, gerando o conflito entre a maternidade e a vida profissional para muitas mulheres.

No caso das idosas do grupo JB, elas decidiram por acumular essas funçóes e terceirizá-las em alguns momentos. Importante destacar que nenhuma dessas mulheres relatou dividir tarefas com o cônjuge ou ter algum tipo de suporte masculino no âmbito doméstico, demonstrando que, embora essas mulheres tenham começado a conquistar a igualdade de direitos, ainda não havia equidade nas relaçôes, conforme o trecho abaixo:

[...] tanto que com dever, era eu quem ajudava os meus filhos, fazia isso, fazia aquilo, eu quem fazia, trabalhava e sofria, ele por exemplo pagava as escolas dos meninos, a alimentação, essas coisas e eu o resto. (Marília, [JB], 2019).

Falar sobre o papel da mulher enquanto esposa, também abrange a sua sexualidade. Embora a maioria das idosas tenham sido casadas, a temática sexualidade foi um aspecto pouco abordado em ambos os grupos, tanto na juventude quanto na velhice. Muitas dessas mulheres náo tiveram educaçáo sexual, sequer receberam orientação dos pais acerca do próprio processo de desenvolvimento, o que é compreensível em se tratando o período histórico em que elas cresceram, no qual falar no corpo e na sexualidade da mulher ainda era tabu (Monteiro, 2020).

Outro ponto que vem reforçar essa perspectiva refere-se à influência cultural, familiar e religiosa que permeia a sexualidade feminina e acaba intensificando em muitas mulheres a ideia de uma não liberdade para se expressar ou agir acerca da sua vida sexual, especialmente na velhice (Debert, 1999; Monteiro, 2020).

De acordo com a narrativa da Nadir, a única das idosas que decidiu năo se casar, o medo de adoecer exerceu um forte impacto na sua vida sexual:

Não, hoje não tenho ninguém. Quietei meu facho [risadas]. Uma coisa que eu falo que pesou muito foi esse negócio de AIDS. Eu peguei um medo, eu tinha um medo da AIDS porque eu tomava... anticoncepcional, mas a camisinha, eu achava aquilo horrível [...] porque não tinha, ninguém falava em AIDS. Aí a partir do momento que aí... nossa! Eu peguei pavor. Eu tinha um medo da AIDS. Que nós começamos a: 'Ó, eu não fazer mais nada, não! Eu vou ficar quieta no meu canto'. Assim, era só... se você conhecesse muito a pessoa, a gente corria o risco, né? (Nadir, [JB], 2019).

$\mathrm{Na}$ narrativa de Nadir, é possível identificar que ela tinha uma vida sexual ativa ao longo da vida, independentemente de ter um parceiro fixo. No entanto, a 
incidência do vírus HIV - Vírus da Imunodeficiência Humana, causador da Síndrome de Imunodeficiência Adquirida, ocorrida a partir da década de 1980 - fora algo que lhe fizera ficar mais seletiva em relação aos parceiros, já que o uso de preservativo não era algo que lhe agradasse. A partir de dados colhidos via DATASUS de pacientes diagnosticados com a doença no período de 1980 a 2000, Leite (2020) trouxe que a incidência da doença em mulheres foi mais alta naquelas com escolaridade analfabeto e fundamental, trazendo à tona o impacto da escolarização e do acesso à informação como fatores de prevenção.

Em relação à maternidade, todas exerceram esse papel, mesmo Nadir que não chegou a ter filhos biológicos. A construção social acerca da associação da mulher à fertilidade e à procriaçáo, foi percebida na fala dessas idosas:

Eu não tive filhos, não casei, não tive filhos e criei... Fui mãe de muitos... mãe postiça de muitos deles... da família, né [...]. Mas eu não aceitava ter um bebê dentro de mim, aquilo me dava um nervoso de eu pensar se eu fosse ficasse grávida, se eu ia ter. Acho que não ia aceitar. Por isso que eu nunca... Eu sempre evitei de todas as maneiras que dava para eu não ficar grávida. Mas eu adorava bebê. Mas bebê. Mas saber que nasceu... Nossa! Eu pensava no parto e falava: 'Eu não. Eu não quero passar por isso'. Eu não quero ter um bebê lá dentro de mim, não quero. (Nadir, [JB], 2019).

[Entrevistadora] - E... você tinha esse sonho de ser mãe?

[Joana] - Tinha. Eu tive treze filhos. Tem dez vivo e morreu três. (Joana, [C], 2019).

$\mathrm{Na}$ fala das mulheres entrevistadas, foi possível perceber que não houve a romantizaçáo acerca da maternidade. No entanto, as do grupo $\mathrm{C}$ demonstraram ter uma visão do ser mãe como consequência natural do casamento e náo relataram fazer uso de métodos contraceptivos. Ao contrário das do grupo JB, que trouxeram esse tipo de informaçáo, o que pôde ser percebido, inclusive, na diferenciaçáo entre o quantitativo de filhos entre os grupos: enquanto no grupo JB, o maior número de filhos foi quatro, no grupo $\mathrm{C}$, esse número chegou a treze.

Outro aspecto importante de se destacar é em relação ao aborto. Amanda, que teve uma filha, trouxe relato sobre seu quadro de saúde e a experiência de ter passado por cinco abortos:

Aí fiz aborto, porque eu não podia tomar pílula, porque eu tinha as mamas muito densa, muito cheia de gânglios, muito... mastite... essas coisas, aí eu não podia tomar a pílula, então tinha que ir pra tabela, isso tudo, aí acabava engravidando, fiz aborto, fiz uns cinco abortos, já era pra eu tá aí com uns seis filhos. (Amanda, [JB], 2019). 
Considerando o contexto histórico em que elas cresceram e a forte influência social e religiosa acerca do corpo feminino, foi interessante observar a naturalidade com que Amanda compartilhou essa parte da sua vida, demonstrando náo ser impactada por possíveis julgamentos sobre as escolhas que fez por interromper as gestaçôes. $\mathrm{O}$ sentimento de culpa ou vergonha são comuns em mulheres que vivenciam experiências de aborto não espontâneo. Podemos compreender esses sentimentos a partir da fala de Vázquez (2014, p. 105):

Ao compreender que nossos corpos possuem um peso social, um peso de um sexo e um peso de gênero pode-se argumentar que as mulheres, cujos corpos, via de regra, são pensados a partir de sua capacidade reprodutiva, estão no centro deste mecanismo de 'peso social' sobre os corpos. Se materializa sobre o corpo feminino o peso de seu gênero, o peso de seu útero.

De forma geral, essas mulheres não trouxeram queixas acerca dos papéis que escolheram exercer ao longo da vida. As idosas do grupo JB, por terem maior escolarização, demonstraram ter uma postura mais ativa em suas vidas, buscando sempre ter suas vozes ouvidas e decisóes respeitadas, quer fosse em casa ou no trabalho. Por outro lado, as idosas do grupo $\mathrm{C}$ trouxeram uma perspectiva mais passiva, embora não o tempo todo.

\section{Velhice satisfatória}

Por fim, vamos compreender as visóes que essas idosas apresentaram sobre velhice satisfatória. Ao final da entrevista de história de vida, elas foram questionadas sobre o que consideravam importante para ser ter uma velhice satisfatória. Seguem a seguir alguns trechos das suas respostas:

Ah, pra ter uma velhice boa tem que ter saúde e ter uma boa memória e ter um pouquinho de dinheiro pra poder sair pra onde quiser... Eu acho que é isso. (Joana, [C], 2019).

Ter uma vida tranquila, filha. Voltou ao começo da sua vida, se você puder ter uma vida tranquila, leva uma vida tranquila. Porque se você tiver... ser tranquila, viver em paz com você mesmo, bem com você mesmo. Em primeiro lugar, gostar de você, que em primeiro lugar tem que gostar da gente. Isso é tudo no mundo. Entấo, você vai dar certo, você vai chegar lá caminhando com dois pés, duas mãos, muito bem, com os poderes de Deus. É... É assim que penso. (Renata, [C], 2019).

Eu acho assim, pra... a gente ter uma velhice com... com sabedoria, com 
responsabilidade, a gente tem que ser uma pessoa muito... É, como é que eu falo? Eh... Que tenha muita fé e que a gente entrega as coisas da gente nas mãos de Deus: 'Senhor, isso aqui, eu sou sua. Faça de mim o que quiser, na sua vontade'. Não queira fazer nada que seja contra Deus, porque ele é o dono de tudo. (Tânia, [C], 2019).

Ah, eu acho que... eu acho que tem. Assim, muito... pessoa tem que ter uma vida, assim... bem. (inint) tudo ter uma vida bem, assim, financeira, mas se a gente tiver Jesus na vida da gente, tiver Deus, um pouquinho de fé, um bocadinho de fé... aí chega. (Fernanda, [C], 2019).

A partir da leitura das narrativas do grupo $\mathrm{C}$, identificamos nove palavras-chave que servem para ilustrar a visão dessas idosas acerca do que seria velhice satisfatória, sendo elas: altruísmo, saber perdoar, ter fé, responsabilidade, sabedoria, boa memória, saúde, autoestima e independência financeira. Como ponto de partida, traremos o altruísmo, o ajudar o próximo. Todas as idosas do grupo $\mathrm{C}$ vivenciaram algum tipo de privaçáo ao longo de suas trajetórias, mas relataram ter recebido menos suporte externo para superar os diversos tipos de obstáculos vivenciados do que o relatado pelo grupo JB. Especialmente após o casamento e a consequente separação do núcleo familiar, essas mulheres demonstraram precisar de estratégias internas para vencer os obstáculos que iam surgindo, utilizando-se pouco de suporte externo. Dessa forma, o ato de se voluntariar e de ajudar a quem precisa apresentou-se como uma forma de elas cuidarem de uma necessidade própria e poder ter o sentimento de satisfaçáo pessoal, a partir do bem-estar do próximo.

Além disso, a influência religiosa apresentou-se como importante aspecto na visão que as idosas do grupo $\mathrm{C}$ apresentaram. Mesmo que não tenham frequentado necessariamente uma igreja (na fase da infância e adolescência, por exemplo), elas tiveram influência da religiosidade, principalmente das religiôes cristás, ao longo de suas vidas. Essa influência pôde ser percebida não apenas na visão de ajudar o outro, como em saber perdoar, valores primariamente voltados à educaçáo religiosa. $\mathrm{O}$ saber perdoar, pela visão de uma das idosas, refere-se à questão de não guardar mágoas ao longo da vida e se permitir seguir em frente, mesmo diante das adversidades. O papel da fé foi algo reiteradamente apresentado no discurso das idosas a partir de falas como: “Do jeito que Deus dava...”, "Graças a Deus”, “...com a ajuda de Deus”. Algumas idosas inclusive destacaram a fé como principal estratégia de enfrentamento das adversidades vivenciadas. Dessa forma, é natural que na velhice a considerem como fator primordial para uma velhice satisfatória.

Quando falamos sobre responsabilidade e sabedoria, foi possível identificar tais aspectos nas próprias trajetórias das idosas. Tomando como exemplo os papéis sociais que essas mulheres exerceram ao longo da vida como filhas, esposas, mães, donas de casa, profissionais, tais características se apresentaram como aspectos indispensáveis 
ao desenvolvimento pessoal e familiar. Essas mulheres nasceram em famílias com alto índice de natalidade (variaçáo de 4 a 15 irmãos), tiveram uma média aproximada de 7 filhos em uma época em que o cuidado familiar era culturalmente exclusivo da mulher. Então, para a maioria delas, além de cuidar das tarefas domésticas, dos filhos, do marido, ainda precisaram contribuir com a renda familiar. A mudança para o Distrito Federal foi um período que exigiu bastante dessas mulheres, especialmente no caso das que vieram sozinhas, após a mudança dos cônjuges. E todas demonstraram extrema responsabilidade e inteligência instrumental para enfrentar os desafios da vida em uma nova cidade, da maternidade e do casamento, por exemplo.

A manutenção de uma boa saúde, uma boa memória e o aspecto financeiro foram aspectos citados por Joana. Ela compartilhou acerca da mudança de vida após o falecimento do marido, tendo maior liberdade e possibilidade de se divertir após chegar à velhice e ainda sobre como lhe fazia bem cuidar da aparência. Trouxe que, embora no passado a vida fora bastante difícil, na atualidade sente que as coisas estấo melhores e ainda tem o desejo em se tornar advogada para ajudar quem precisa.

Por fim, a autoestima foi apresentada por Renata como aspecto para se ter uma velhice satisfatória. Como ela apresentou: "Em primeiro lugar, gostar de você, que em primeiro lugar tem que gostar da gente. Isso é tudo no mundo". O interessante da trajetória de Renata é que ela se casou muito jovem, teve um relacionamento complicado com o marido e, assim como Joana, afirmou ter começado "a viver depois de velha", ou seja, após ficar viúva. Um ponto interessante da narrativa dessa idosa é a reflexão que ela faz sobre o impacto da melhoria no acesso a bens e serviços em contraposição à sensação de perda de liberdade: "Hoje em dia, a "vida é boa, tem conforto, tem tudo, tem mais facilidade [...]. Mas é uma vida muito presa”.

Ah, eu acho que para uma velhice satisfatória o que pesa é a saúde, né? É a saúde. Então, se você tem saúde você náo tem... Outra coisa que eu acho da velhice satisfatória que eu... é o que eu tive... Não tinha cobrança, eu não tinha... que eu falo... (Nadir, [JB], 2019).

Uma velhice satisfatória? Olha, eu acho assim... Uma velhice que tenha o apoio da família, que tenha uma situação que dê conforto, que você tenha uma assistência médica, acho fundamental. Ter uma vida saudável, mas principalmente que você tenha amigos para se encontrar, que te tire de casa, que te resgate naqueles momentos em que você está desanimada... 'Tồ aqui! Tô aqui! Vem para cá!' 'Não, tô afim, não.' 'Vou aí te buscar!' Acho que isso aí é fundamental. (Amanda, [JB], 2019).

Em primeiro lugar, saúde, e em segundo lugar independência. (Marília, [JB], 2019). 
Então, eu acho que se você tem a sua família perto de você, você tem amigos [...]. Então eu acho que o pior da velhice é isso, você não ter aquele... aquele companheirismo [...]. Eu acho que o mais importante é isso, é ter apoio financeiro e social, ajudar, levar pros cantos, não é enfiar dentro de casa. (Marta, [JB], 2019).

As idosas desse grupo apresentaram uma perspectiva mais ampla sobre a visão de velhice satisfatória, abrangendo aspectos tanto extrínsecos quanto intrínsecos. As dificuldades vivenciadas por essas mulheres ao longo da infância e adolescência se mostraram como elementos motivadores para que elas construíssem seus projetos de vida e buscassem no estudo a construção de uma vida com independência.

No aspecto da renda, a disparidade socioeconômica entre os grupos favoreceu na manutençáo do status quo para as participantes do grupo JB: a maioria delas conseguiu se aposentar cedo ou, ainda, recebiam pensáo após falecimento do marido. Mesmo assim, a questão financeira foi pontuada por apenas duas participantes. Amanda complementou sua visăo da seguinte maneira: "Eu queria dinheiro. Saúde e dinheiro, tá bom."

$\mathrm{O}$ aspecto da saúde foi levantado por três das idosas como principal fator relacionado à percepçáo de velhice satisfatória. Nadir trouxe em sua narrativa fatos acerca do impacto da perda dos pais e da irmã, sendo que todos faleceram devido a questôes de saúde, e Marília teve uma filha com quadro de poliomielite. Amanda complementou esse aspecto da saúde no quesito da assistência médica. Sua trajetória foi marcada pelo adoecimento do marido, o qual cuidou por quase 20 anos até ele falecer, e pelo quadro de câncer que teve, tendo se submetido a cirurgia.

No que tange à rede de apoio social, as idosas do grupo JB puderam contar com o apoio da família nuclear mesmo após o casamento e eram pessoas com bom relacionamento interpessoal, tendo relaçóes sólidas com os amigos e colegas de trabalho. Além disso, o fato de participarem de um grupo de convivência, terem uma vida social ativa e realizarem diversas atividades como festas, viagens, novenas, pode justificar a valorizaçáo que essas mulheres deram a esse aspecto como critério para uma velhice satisfatória. Os fatores alegria, flexibilidade e independência demarcam características da personalidade dessas mulheres que buscaram viver a vida tendo esses pontos como princípios.

Um aspecto interessante levantado pela maioria das participantes desse grupo foi o fato de não se enxergarem como velhas, assim como afirma Marta: "Não sinto que estou ficando velha". Essa compreensão pode ser justificada pelo fato de elas carregarem a visão de que o velho é um indivíduo sem autonomia, independência e vitalidade. Nadir ainda complementa trazendo sobre sua idade psicológica: "Eu acho que tenho de 40 para 50 anos. Eu não cheguei nos 60 ainda não [risadas]." No entanto, mesmo vivenciando o conflito em aceitar a velhice, elas buscaram se adaptar de melhor forma possível, demonstrando que o mais importante dessa fase para elas é poder ter liberdade, conforme a fala de Marta: "Mas, eu nesse ponto eu não tenho trauma nenhum, náo quero ser mais nova, não quero fazer plástica, nada disso, entendeu? Eu quero viver a vida."

A partir dessa perspectiva, concluímos com a fala de Motta (1999), que afirma que 
a condição de ser jovem ou velho pode ser vivida de forma distinta a partir da influência de gênero e classe social. Nesse sentido, a trajetória de homens e mulheres, construída cultural e socialmente, apresenta diferentes representaçóes e atitudes acerca do que é ser velho.

\section{Considerações finais}

O nosso objetivo neste artigo foi trazer, a partir da perspectiva teórica do envelhecimento ao longo de toda a vida, a visão que essas mulheres idosas tinham acerca da sua velhice, observando se a classe social foi um fator determinante ou não nessas compreensóes. Diante disso, trabalhar com história de vida permitiu a compreensão aprofundada da complexidade de valores, crenças, emoçóes e experiências de oito mulheres de diferentes classes sociais acerca de suas trajetórias de vida e a construção de uma velhice satisfatória.

Os resultados apresentados neste artigo corroboram com o papel da rede social de apoio - especialmente da família -, da espiritualidade e da saúde como principais pontos na visão de idosos para se ter uma velhice satisfatória (Oliveira et al., 2020; Largueiras, 2020; Moura; Delgado; Mármora, 2018; Portella et al., 2017). Embora todas as idosas tenham vivenciado diversas adversidades ao longo da vida, a velhice tem sido uma etapa da vida permeada pelo acesso a oportunidades educacionais e a novos bens e serviços para o grupo da Ceilândia; enquanto para o grupo do Jardim Botânico, tem representado um período de descanso e de usufruir do lazer e da companhia dos familiares e amigos.

Destaca-se nesse processo de envelhecimento a vivência subjetiva e pautada em parâmetros sociais que podem ser mediados pela forma como a velhice vem sendo experienciada, resultando em um período de realizaçóes e desenvolvimento pessoal. Deste modo, a construção de uma velhice satisfatória demonstrou ser subsidiada pelo conjunto de experiências acumuladas ao longo da vida.

A classe social não se apresentou como fator preponderante na forma como as mulheres definem uma velhice satisfatória. No entanto, esse foi um critério que demarcou diversas desigualdades ao longo de toda a trajetória das mulheres da Ceilândia e foi um facilitador para as mulheres do Jardim Botânico. Dessa forma, assim como afirma Abigail (2020), o acesso a políticas sociais ao longo de todo o curso de vida se apresenta como essencial ao processo de envelhecer com qualidade, embora, na prática, esse não é um aspecto assegurado para a grande maioria das pessoas idosas no Brasil. Assim, a promoçáo de novos estudos que tragam essa discussão à tona faz-se necessária a fim de que possamos reduzir a disparidade social existente entre os idosos brasileiros.

Enquanto pesquisadores, vemos a dificuldade de manter a fidedignidade em relação à essência das narrativas ao transcrevê-las e apresentá-las ao leitor, isso porque entendemos 
que passamos a apresentar recortes e organizá-los de forma a tornar o todo compreensível. Além disso, as trajetórias que essas mulheres compartilharam nos permitiriam entrar em discussóes acerca de diversas temáticas além das que foram apresentadas, assim como observamos o desafio em aprofundar teoricamente todas as categorias citadas por serem temas amplos e que não se esgotam em poucas linhas de um artigo. De toda forma, as categorias apresentadas podem pavimentar novas reflexóes a respeito da trajetória de vida de mulheres ao longo do século XX e início do século XXI, bem como debates teóricos sobre a velhice satisfatória.

\section{Referências}

ABIGAIL, Albamaria Paulino de Campos. Contrarreforma da Seguridade Social no Brasil e as suas implicaçôes para as pessoas idosas: destaque às políticas de Previdência e Assistência Social. In: MUSIAL, Denis Cesar et al. (Org.). Políticas sociais e gerontologia: diálogos contemporâneos. Maringá: Uniedusul, 2020. E-book. p. 127-146.

ALBERTE, Joseane Souza Pinto. Fatores biopsicossociais no envelhecimento e percep̧̧ão da qualidade de vida do idoso. Tese (Doutorado em Ciências Médicas) - Unicamp, Campinas, SP, 2009.

AZEVEDO, Mileane Andrade; SOUSA, Luciano Dias de. Emponderamento como representatividade das mulheres na sociedade. Coisas do Gênero, Sáo Leopoldo, v. 5, n. 1, p. 170-178, 2019. Disponível em: http://periodicos.est.edu.br/index.php/genero/article/ view/3633/3187. Acesso em: 18 maio 2021.

BIAGIONI, Daniel. Mobilidade social e migração interna no Brasil. Rio de Janeiro, 2010. Disponível em: https://centrodametropole.fflch.usp.br/sites/centrodametropole.fflch.usp.br/ files/user_files/noticias/ckeditor/daniel_biagioni.pdf. Acesso em: 18 maio 2021.

BILGE, Sirma. Théorisations féministes de l'intersectionnalité. Diogène, v. 225, n. 1, p. 70-88, 2009.

CAMARGO, Merielli Casagrande et al. Beliefs, perceptions, and concepts of old age among participants of a University of the Third Age. Psychology \& Neuroscience, v.11, n. 4, p. 417-425, 2018.

CARVALHO, Juliana Castro Benício de; COSTA, Liana Fortunato. História de vida: aspectos teóricos da Psicossociologia clínica. Revista Brasileira de Psicodrama, São Paulo, v. 23, n. 2, p. 2431, 2015. Disponível em: http://pepsic.bvsalud.org/scielo.php?script=sci_arttext\&pid=S0104$53932015000200004 \& \operatorname{lng}=\mathrm{pt} \& \mathrm{nrm}=\mathrm{iso}$. Acesso em: 18 maio 2021.

CHO, Sumi; CRENSHAW, Kimberlé Williams; McCALL, Leslie. Toward a Field of Intersectionality Studies: Theory, Applications, and Praxis. Signs, v. 38, n. 4, p. 785-810, 2013.

DAVID, Priscila. História oral: metodologia do diálogo. Patrimônio e Memória, Assis, v. 9, n. 1, p. 157-170, 2013. Disponível em: https://pem.assis.unesp.br/index.php/pem/article/view/313. Acesso em: 18 maio 2021.

DEBERT, Guita Grin. A reinvenção da velhice. Sáo Paulo: Editora da Universidade de São Paulo: 
Fapesp, 1999.

FIGUEIREDO, Luiz Orencio; ZANELATTO, João Henrique. Trajetória de migraçóes no Brasil. Acta Scientiarum. Human and Social Sciences, Maringá, v. 39, n. 1, p. 77- 90, 2017. Disponível em: https://www.redalyc.org/articulo.oa?id=307350907009. Acesso em: 2 fev. 2020.

GUEDES, Simoni Lahud. Vidas revisitadas: a reconstrução do passado de idosos em programas gerontológicos. Sociologia \& Antropologia, Rio de Janeiro v. 4, n. 1, p. 233-255, 2014. Disponível em: www.scielo.br/pdf/sant/v4n1/2238-3875-sant-04-01-0233.pdf. Acesso em: 14 out. 2018.

HIRATA, Helena. Gênero, classe e raça. Tempo Social, v. 26, n. 1, p. 61-73, 2014.

LARGUEIRAS, Joana Isabel Bagorrilha. Satisfação com a vida nos idosos: influência da frequência do uso de espaços verdes e do contacto com as redes sociais. Dissertaçáo (Mestrado em Psicologia Clínica) - Universidade de Évora, Escola de Ciências Sociais, Évora, PT, 2020. Disponível em: http://hdl.handle.net/10174/28154. Acesso em: 23 fev. 2021.

LEITE, Daniela Soares. A AIDS no Brasil: mudanças no perfil da epidemia e perspectivas. Brazilian Journal of Development, São José dos Pinhais, v. 6, n. 8, p. 57382-57395, 2020.

LEITE, Valéria de Jesus; SILVA, Rosane Marçal da; LIMA, Cintia Fiorotti. Experiências de pesquisa com trabalhadoras e trabalhadores por meio de fontes orais na História Social: caminhos e possibilidades. Revista História Oral, v. 23, n. 2, p. 243-258, 2020.

LIMA, Fabiana Moreira. Trajetórias do envelhecimento: a construção de uma velhice satisfatória sob a perspectiva de mulheres idosas de diferentes classes sociais. Dissertação (Mestrado em Gerontologia) - UCB, Brasília, DF, 2020. Disponível em: https://bdtd.ucb.br:8443/jspui/ bitstream/tede/2762/2/FabianaMoreiraLimaDissertacao2020.pdf. Acesso em: 18 maio 2021.

MACHADO, Marília Novais da Mata. Intervenção psicossociológica, método clínico, de pesquisa e de construção teórica. Pesquisas e Práticas Psicossociais, São João del-Rei, v. 5, n. 2, p. 175-181. 2010. Disponível em: https://www.ufsj.edu.br/portal2-repositorio/File/revistalapip/ volume5_n2/Mata_Machado.pdf. Acesso em: 18 maio 2021.

MEIHY, José Carlos Sebe Bom. Manual de história oral. 3. ed. São Paulo: Ediçôes Loyola, 2000.

MONTEIRO, Yohana Tórres. Sexualidade das mulheres em envelhecimento: um tabu? Brazilian Journal of Development, São José dos Pinhais, v. 6, n. 3, p. 13129-13137, 2020.

MOTTA, Alda Britto da. As dimensóes de gênero e classe social na análise do envelhecimento. Cadernos Pagu, Campinas, n. 13, p. 191-221, 1999.

MOURA, Elaine Andrade; DELGADO, Francisco Eduardo Fonseca; MÁRMORA, Cláudia Helena Cerqueira. Representaçóes sociais da satisfação com a vida de idosos aposentados. Revista HUPE, v. 17, n. 2, p. 7-15, 2018. Disponível em: http://bjhbs.hupe.uerj.br/WebRoot/pdf/672_ pt.pdf. Acesso em: 23 fev. 2021.

OLIVEIRA, Daniel Vicentini de et al. Fatores associados à satisfação com a vida de idosos usuários de Unidades Básicas de Saúde. Revista Psicologia e Saúde, v. 12, n. 2, p. 19-29, abr./jun. 2020.

PORTELLI, Alessandro. O que faz a história oral diferente. Projeto História, Sáo Paulo, v. 14, p. 25-39, 1997. Disponível em: https://revistas.pucsp.br/revph/article/viewFile/11233/8240. Acesso 
em: 18 maio 2021.

SILVA, Aline Pacheco et al. "Conte-me sua história”: reflexôes sobre o método de História de Vida. Mosaico, Belo Horizonte, v. 1, n. 1, p. 25-35, 2007. Disponível em: https://periodicos.ufmg.br/ index.php/mosaico/article/view/6224. Acesso em: 18 maio 2021.

SILVA, Haike Roselane Kleber da. Consideraçóes e confusóes em torno de história oral, história de vida e biografia. MÉTIS: História \& Cultura, Caxias do Sul, v. 1, n. 1, p. 25-38, 2002. Disponível em: http://www.ucs.br/etc/revistas/index.php/metis/article/view/1037. Acesso em: 18 maio 2021.

VÁZQUEZ, Georgiane Garabely Heil. Sobre os modos de produzir as mães: notas sobre a normatização da maternidade. Mosaico, Goiânia, v. 7, n. 1, p. 103-112, 2014. Disponível em: http://seer.pucgoias.edu.br/index.php/mosaico/article/view/3984. Acesso em: 18 maio 2021.

VICENTE, Teresa Aracena. As mulheres e seus tempos: dupla jornada de trabalho, cuidado de si e lazer na promoção da saúde. Tese (Doutorado em Ciências) - USP, Faculdade de Medicina, São Paulo, SP, 2018.

\section{Fontes orais}

AMANDA [79 anos]. [jul. 2019]. Entrevistador: Fabiana Lima. Brasília, DF, 25 jul. 2019.

FERNANDA [68 anos]. [ago. 2019]. Entrevistador: Fabiana Lima. Ceilândia, DF, 21 ago. 2019.

JOANA [73 anos]. [ago. 2019]. Entrevistador: Fabiana Lima. Ceilândia, DF, 17 ago. 2019.

MARÍLIA [82 anos]. [ago. 2019]. Entrevistador: Fabiana Lima. Brasília, DF, 1 ago. 2019.

MARTA [81 anos]. [ago. 2019]. Entrevistador: Fabiana Lima. Brasília, DF, 8 ago. 2019.

NADIR [71 anos]. [maio 2019]. Entrevistador: Fabiana Lima. Brasília, DF, 9 maio 2019.

RENATA [72 anos]. [ago. 2019]. Entrevistador: Fabiana Lima. Ceilândia, DF, 18 ago. 2019.

TÂNIA [70 anos]. [ago. 2019]. Entrevistador: Fabiana Lima. Ceilândia, DF, 27 ago. 2019.

Recebido em 28/02/2021.

Versão final reapresentada em 29/04/2021.

Aprovado em 04/05/2021.

Contribuiçáo dos autores: Lima: coleta, análise e síntese das entrevistas, pesquisa bibliográfica, redação; Salmazo-Silva: pesquisa bibliográfica, redação e revisão do texto.

Certificado de Apresentaçáo de Apreciaçáo Ética (CAAE): 02082018.6.0000.0029

Fonte de financiamento: nada a declarar.

Conflitos de interesse: nada a declarar. 